\title{
The body, emotions and intentions: challenges of preconception arrangements for health care providers
}

\section{Juliet Guichon}

$\infty \quad$ See related article page 483

$\mathrm{D}$ an Reilly has written an important article in this issue of CMAJ for medical practitioners who manage the health care of pregnant women intending to surrender the child once born. ${ }^{1}$ In addition to providing an accurate overview of the law, Reilly summarizes a range of ethical opinions and concludes correctly that there is not yet a consensus. He advises prenatal health care providers to be attentive to unusual problems that may arise and recommends that the pregnant woman be carefully monitored for obstetric and psychological complications. Health care providers are urged to request social work, ethical and legal support at the first hint of difficulty. However, Reilly's review has 3 limitations from a general societal perspective. These limitations are discussed below and are followed by suggestions for health care providers about the management of these unusual obstetrics patients.

First, the terminology used in Reilly's review potentially masks important ethical and legal considerations. The description of a pregnant woman as a "surrogate" without further discussion is prejudicial, because it suggests that she has no claim to maternity. In addition, the term "contract" should not be used when discussing preconception arrangements. The use of "contract" incorrectly implies that commercial law would govern in a disputed case, when in fact, family law would apply. Moreover, the word "contract" wrongly suggests that the deal can be enforced by law, even though no Canadian province has done so. Contract law is an essential tool of commerce and regards a deal as a deal. It assumes that people are autonomous, rational, self-interested and equal. However, family law accepts that people are interdependent, capable of irrationality, self-giving and vulnerable. Family law focuses on the body, emotions and changing intentions; it supervises the unravelling of solemnly made marriage vows in divorce and places the needs of children first - irrespective of shifting adult intentions. The same is true of preconception arrangements. ${ }^{2,3}$

Second, Reilly's suggestion that preconception arrangements are not relatively easy to study does not match the reality of infertility treatment. Although some commissioned conceptions occur privately, where, for example, a turkey baster or sexual intercourse initiate conception, this is probably unusual. Many, if not most, commissioned conceptions are initiated in fertility clinics, where a genetically unrelated embryo is transferred into a woman who intends to relinquish the resulting child at birth. In other words, most commissioned pregnancies probably occur because of the intervention of skilled professionals. As a consequence, the long-term effects of commissioned pregnancy can and should be studied because of the vulnerability of all parties involved, and because our society is the first in human history to put maternity in doubt.

The third limitation of Reilly's review is that its summary of ethical opinion neglects statements made by adult offspring. To date, assessments of the morality of preconception arrangements have focused on the adults involved and, in particular, on whether a woman's autonomy is enhanced or limited when she deliberately conceives a child that will be surrendered after birth. But some "products" of these arrangements - adult offspring - are now beginning to speak out, decrying the lack of concern for their welfare:

She willingly gave me away. What made me so unloveable? Was I ugly? Well you laugh at that, but really — what was it? Here I was born around the time of the Baby M fiasco. I have never told anyone this, but I am so jealous of Baby M. Her mum fought for her straight away. She could not bear to part with her. Why couldn't that have been $m e ?^{4}$

Talk until you are blue in the damn face about how I was wanted and loved and how I was given as a gift blah blah blah. It doesn't matter because, guess what, your words tell me "loved and wanted," your actions tell me "abandoned and traded." Actions speak louder than words. ${ }^{5}$

Consider also this lament by an adult to his birth mother and others:

You don't bond with us when you are carrying us and you deny that we are yours because you have deluded yourselves [...] How do you think that makes us kids feel? You may be able to deny us but we don't want to deny who you are. That makes us feel very rejected. That leaves a hole in our hearts whether we admit to it or it manifests some other way like in depression or a fear of getting close to someone else. $^{6}$

One hopes that the Assisted Human Reproduction Agency of Canada will require long-term studies, especially those involving the children as they progress into early adulthood and beyond. $^{7}$

\section{Specific suggestions for health care providers}

\section{Meet with the patient alone to discuss her rights}

At the first meeting, the health care provider should excuse the couple or person hoping to rear the child (hereinafter the "commissioner[s]") from the room, thus permitting a 
discussion of what role, if any, the pregnant woman would like the commissioner(s) to play. As Reilly recommends, the health care provider should tell the patient that, because the pregnancy is in her body, she alone decides. Likewise, only she can give permission to disclose confidential medical information, and she may change her mind at any stage. The health care provider should focus on developing a trusting relationship with the pregnant woman to address the possibility of coercion. This could occur even among family or friends, for example, by enticement, threat or payment (though payment is expressly forbidden by Canadian law). ${ }^{8}$ If the arrangement has been documented or payment has been made, the pregnant woman may wrongly believe that she has entered into a binding contract and, therefore, may no longer feel free to determine her future.

The health care provider should continually remind the pregnant woman that Canadian provincial law has always protected a birth mother's right to keep or to relinquish the baby (in the absence of a judicial finding of maternal unfitness). Depending on provincial law, the birth mother has a period of time during which she may change her mind and have the baby returned to her.

If the pregnant woman is carrying an embryo created from another woman's ovum, then she is entering into predominantly unchartered legal territory. In Quebec, she is the legal mother. ${ }^{9}$ Elsewhere in Canada, the law has not yet been clarified by a court case. But to ask "who is the real mother?" is both illogical and unhelpful when both the ovum provider and the pregnant woman share the role of biological mother. Health care providers should help the pregnant woman reframe the question from the perspective of the most vulnerable party - the child. The important question is "why should either mother be excluded from the child's life?" People who create a family using 3 or more parties should adapt to the fact that the resulting family will not be a traditional one. If the birth mother relinquishes the child, the commissioner(s) should permit the child to have an ongoing relationship with the birth mother for the same reason that adoption professionals now encourage openness: to help the adoptee develop a more complete sense of identity. ${ }^{10}$

Allowing the pregnant woman to maintain contact with the child after birth would also benefit her. A recent review of the long-term effects on women who give up a child following preconception arrangements suggests that a positive outcome for these women depends, in part, on maintaining relationships. ${ }^{11}$ According to van den Akker, "most surrogate mothers expected some contact between them to continue following relinquishment of the baby, so that they maintained their new friendships and their children could still see the [resulting baby] ... Unfortunately, in some cases, this contact ceased unexpectedly after the legal proceedings had been completed [which was] seen as a betrayal." ${ }^{11}$ This conclusion is corroborated by an earlier longitudinal study that found that the quality of the relationship with the commissioner(s) after birth may influence the degree of long-term satisfaction and regret of women who surrender children in a preconception arrangement. ${ }^{12}$

\section{Address psychological issues the pregnant woman may be experiencing}

Given the intentions when the embryo was created, the pregnant woman may initially be determined to relinquish the child once it is born. But as the pregnancy develops, she may feel and think otherwise. Health care providers need to be attentive to a change of attitude because women's feelings routinely change during pregnancy. This attention is especially necessary given the unusual vulnerability of the parties. For example, the commissioner(s) may expect to be in the delivery room and to be handed the baby before the formerly pregnant woman sees it, and though the pregnant woman may initially agree to this, she may change her mind during the pregnancy.

Health care providers should also be alert to the development of unusual symptoms because a preconception arrangement is, itself, unusual. It requires a pregnant woman to respond extraordinarily and compassionately to the commissioner(s) while suppressing a normal desire to respond ordinarily and naturally to the baby. Such a situation may result in changes in the behaviour of the pregnant woman. The negative effects of the unusual conflict of loyalties and obligations may extend to the pregnant woman's children. Maintaining a relationship with the baby may help to diminish their grief because "It would be naive to think that the children of the incubating family will be unaffected by the loss." ${ }^{13}$

\section{Continually review whether the pregnant woman has adequate emotional assistance}

Health care providers should also ask the pregnant woman about her psychological support system. If she has a partner, it is important to enquire about the effects of the preconception arrangement on the partner (keeping in mind that the partner's consent is not relevant to the pregnant woman's medical treatment). ${ }^{14}$ The pregnant woman's partner must make accommodations for the woman's physical and psychological changes, but because a third party fathered the fetus, the partner may feel excluded, resentful and jealous. Such feelings might be exacerbated if the birth mother chooses to keep the child. The preconception arrangement has the potential to end their relationship. As in other pregnancies, medical practitioners should also be alert to any signs of abuse. ${ }^{15}$

\section{Conclusion}

All parties involved in a preconception arrangement are vulnerable, especially the children. Although the pregnancy and birth may be a positive experience and create a "happy family" for the commissioner(s), this arrangement may result in grief for the birth mother and her family. The birth mother may experience a significant and enduring sense of loss if she is not permitted to continue a relationship with the baby. By discarding the fictional belief that preconception arrangements create traditional nuclear families and 
that the relationship between the birth mother and child can be ruptured without effect, health care providers will be better prepared to deal with the challenges presented by preconception arrangements.

This article has been peer reviewed.

Juliet Guichon is with the Office of Medical Bioethics, Faculty of Medicine, University of Calgary, Calgary, Alta.

Competing interests: None declared.

\section{REFERENCES}

I. Reilly DR. Surrogate pregnancy: a guide for Canadian prenatal health care providers. $C M A J 2006 ; 176(4): 483-5$

2. Guichon J. 'Surrogate' motherhood, legal and ethical analysis. In: Legal and ethical issues in new reproductive technologies: pregnancy and parenthood. Vol 4. Ottawa: Royal Commission on New Reproductive Technologies;1993.

3. Guichon J. An examination and critique of the contract model of legal regulation of preconception arrangements and a proposal for law reform in Ontario [dissertation]. Toronto: University of Toronto; 1997.

4. “A proper bang" [Weblog entry]. 2006 Mar 22. Available: http://umbliclychallenged .blogspot.com/2006/03/proper-bang.html (accessed 2007 Jan 2).
5. "Removes the mystery, but not the grief" [Weblog entry]. 2006 Aug 8. Available: http://umbliclychallenged.blogspot.com/2006/08/removes-mystery-but-not-grief o8.html (accessed 2007 Jan 2).

6. "The son of a surrogate" [Weblog entry]. 2006 Aug 9. Available: http://sonofasurrogate.tripod.com/ (accessed 2007 Jan 4).

7. Health Canada. Assisted Human Reproduction Agency of Canada [news release]. June 2005. Available: www.hc-sc.gc.ca/ahc-asc/media/nr-cp/2005/2005_67bki_e. html (accessed 2007 Jan I2).

8. Assisted Human Reproduction Act, SC 2004, c 2, S 6(I).

9. Quebec Civil Code, SQ ig9i, C 64.

Io. Sullivan R, Lathrop E. Openness in adoption: retrospective lessons and prospective choices. Child Youth Serv Rev 2004;26:393-4II.

II. Van den Akker OB. Psychosocial aspects of surrogate motherhood. Hum Reprod Update 2007;13:53-62.

I2. Reame N. Long-term satisfaction and outcomes after surrogate pregnancy [conference presentation] International Federation of Fertility Societies (IFFS) I6th World Congress on Fertility and Sterility/American Society for Reproductive Medicine (ASRM) 54th Annual Meeting. I998 October; San Francisco.

I3. Steadman JH, McCloskey GT. The prospect of surrogate mothering: clinical concerns. Can J Psychiatry I987;32:545-50.

I4. Tremblayv. Daigle (I989), SCR, 530.

I5. MacMillan HL. Physical abuse during pregnancy: a significant threat to maternal and child health. CMAJ I999;160:I022-3.

Correspondence to: Juliet Guichon, Office of Medical Bioethics, Heritage Medical Research Building, 3330 Hospital Dr. NW, Calgary $A B \quad T_{2} N_{4} N I$; fax 403 283-8524; guichon@ucalgary.ca 